\title{
Multiple micronutrient supplementation and dietary energy intake in pregnant women
}

\author{
María de Lourdes Flores, MS,(1) Lynnette M Neufeld, PhD, (I) Teresa González-Cossío, PhD, (I) \\ Juan Rivera, PhD, (I) Reynaldo Martorell, PhD, (2) Usha Ramakrishnan, PhD. (2)
}

\author{
Flores ML, Neufeld LM, González-Cossío T, \\ Rivera J, Martorell R, Ramakrishnan U. \\ Multiple micronutrient supplementation \\ and dietary energy intake in pregnant women. \\ Salud Publica Mex 2007;49:190-198.
}

\begin{abstract}
Objective. To compare dietary intake of women supplemented with multiple micronutrients (MM) or iron only during pregnancy. Materials and Methods. Design: Randomized, double-blind, controlled community-based trial. Setting: One semi-urban community in Central Mexico. Subjects: Pregnant women identified before week 13 of pregnancy, willing to provide informed consent. Interventions:Women were randomly assigned to receive daily supplementation with MM or iron only from recruitment until delivery. Supplements were delivered to the participants' home and compliance observed daily. Dietary intake was assessed by repeat 24-hr recall. Data were analyzed using non-parametric tests and multiple regression analysis to determine the impact of MM supplementation on dietary intake of energy and select micronutrients. Results. During the third trimester, women in the MM group consumed more energy and iron from dietary sources than women in the iron only group. After adjustment for differences between the groups at baseline, women in the MM group consumed III.3 kcal/day more $(p<0.05)$ energy. The difference in iron intake was not significant after adjusting for the increase in energy intake. Conclusions. Women consuming MM supplements during pregnancy increased energy intake from dietary sources without a concurrent increase in micronutrient density. Future studies should include
\end{abstract}

Flores ML, Neufeld LM, González-Cossío T, Rivera J, Martorell R, Ramakrishnan U.

Suplementación con micronutrimentos múltiples y consumo de eneregía en mujeres embarazadas. Salud Publica Mex 2007;49:190-198.

\section{Resumen}

Objetivo. Comparar la dieta de mujeres suplementada con múltiples micronutrimentos (MM) o sólo con hierro durante el embarazo.Material y métodos. Diseño: ensayo comunitario, aleatorizado, controlado, doble ciego. Lugar: una comunidad semiurbana en el México central. Participantes: mujeres embarazadas identificadas antes de la semana 13 de embarazo, dispuestas a entregar el consentimiento informado. Actividades: las mujeres fueron asignadas en forma aleatoria a recibir suplementación diaria con MM o exclusivamente hierro desde el reclutamiento hasta el parto. Los suplementos se entregaron en la casa de las participantes y se observó su cumplimiento con frecuencia diaria. El consumo dietético fue valorado por mediciones repetidas de recordatorio de alimentos de $24 \mathrm{~h}$. Los datos se analizaron mediante pruebas no paramétricas y análisis de regresión múltiple, para determinar el impacto de la suplementación MM en el consumo dietético de energía y micronutrimentos seleccionados. Resultados: durante el tercer trimestre, la mujer asignada al grupo MM consumió más energía y hierro de fuentes dietéticas que la mujer asignada al grupo de sólo hierro. Después de los ajustes para las diferencias entre grupos en la línea basal, la mujer del grupo MM consumió III.3 kcal/día más $(p<0.05)$ de energía. La diferencia en el consumo de hierro no fue significante después de los ajustes para el incremento en el consumo de

(I) Center for Nutrition and Health Research, National Institute of Public Health. Mexico.

(2) Department of International Health, Rollins School of Public Health, Emory University. USA.

Received on: March 23, 2006 Accepted on: January 24, 2007

Address reprint requests to: Dra. Lynnette Neufeld. Dirección de Epidemiología de la Nutrición, Instituto Nacional de Salud Pública. Av. Universidad 655, col. Santa María Ahuacatitlán. 62508 Cuernavaca, Morelos, México.

Email:neufeld@insp.mx 
measures of appetite and physical activity during pregnancy to determine the implications of additional energy intake for weight gain and retention.

Key words: multiple micronutrients; iron; supplementation; randomized controlled trial; dietary intake; energy intake; Mexico energía. Conclusiones: la mujer que consume suplementos MM durante el embarazo aumenta el consumo de energía a partir de fuentes dietéticas sin un incremento concurrente en la densidad de micronutrimentos. Estudios futuros deberían incluir mediciones del apetito y de la actividad física durante el embarazo para determinar las consecuencias del consumo de energía adicional en la ganancia de peso y la retención.

Palabras clave: micronutrimentos múltiple; hierro; suplementación ensayo controlado aleatorizado; consumo dietético; consumo energético; México
D etary requirements of energy and micronutrients are elevated during pregnancy to support changes in maternal tissue and fetal growth. ${ }^{1}$ Inadequate dietary intake may lead to compromised maternal and/ or fetal health. ${ }^{2}$ Because the prevalence of deficiency is high and adequate intake from dietary sources may be difficult to obtain for some nutrients, for example, iron, ${ }^{3}$ micronutrient supplementation is often recommended during pregnancy. ${ }^{4}$ In Mexico, despite the high prevalence of overweight and obesity, micronutrient malnutrition in women of childbearing age continues to be an important public health problem. ${ }^{5,6}$

Micronutrient supplementation may influence appetite $^{7}$ and as a result, dietary intake. Although evidence that appetite increases as a result of micronutrient supplementation exists in the published literature for the elderly, ${ }^{8}$ children $^{9}$ and individuals with cancer, ${ }^{10,11}$ results are not consistent. ${ }^{12}$ Studies supporting the effect of micronutrient supplementation on appetite and, more specifically, on dietary energy intake during pregnancy are scarce. Higher energy intake during pregnancy as a result of micronutrient supplementation could have positive impacts on maternal and fetal outcomes where maternal malnutrition is common. However, where a high prevalence of overweight and / or obesity are combined with prevalent micronutrient deficiencies -such as the situation in Mexico- this may be undesirable.

The purpose of the current analysis was to determine the impact of daily supplementation with multiple micronutrients (MM) compared to supplementation with iron only during pregnancy in a randomized, controlled trial on dietary intake of energy, iron, zinc, folic acid, and vitamins A and C.

\section{Material and Methods}

A randomized, double-blind, controlled trial was conducted from 1997 to 2000 in a semi-urban community in central Mexico. The principal objective of the study was to compare the impact of daily supplementation with MM or iron only on fetal growth. Details of study design are published elsewhere. ${ }^{13}$ Briefly, women were recruited before 13 weeks pregnancy (based on recalled date of last menstrual period, verified by ultrasound when possible) and were randomly assigned to receive MM or iron supplementation. All women were explained the objectives, procedures, risks and benefits of the study and were invited to participate. Willing participants were asked to sign an informed consent declaration. Women taking other nutritional supplements during pregnancy were excluded from the study. The study protocol was approved by the Emory University and the National Institute of Public Health, Mexico (INSP) Human Subjects Commissions.

Randomization was carried out by using four color-coded groups (two per treatment). Lists of group assignments were generated a priori with a computer random number generator and women were sequentially assigned to a group based on these lists. Four colors were used to reduce the possibility of unmasking during field work and analysis. All field and laboratory personnel and investigators were blinded to the group assignment, the details of which were held by researchers not involved in the study at Emory University and the INSP in sealed envelopes that were opened only after preliminary data analysis was completed.

Supplement tablets were identical; both contained $60 \mathrm{mg}$ of ferrous sulfate and were coated to avoid gastrointestinal discomfort. The MM also contained 1.0-1.5 $\mathrm{RDA}^{14}$ of vitamins $\mathrm{A}, \mathrm{D}, \mathrm{E}, \mathrm{C}, \mathrm{B}_{1}, \mathrm{~B}_{2}, \mathrm{~B}_{6^{\prime}} \mathrm{B}_{12}$, niacin, folic acid, magnesium and zinc. Supplements were distributed $6 \mathrm{~d} /$ week from recruitment to delivery by study nurses and compliance was observed on a daily basis. The supplements were developed at and donated by Laboratorios Zerboni in Mexico City with premix donated by Roche Vitamins, Mexico. 
Dietary intake at recruitment (4-13 weeks) and during the third trimester of pregnancy (26-40 weeks) was estimated using repeat 24-h recalls (2) on non-consecutive days, excluding weekends and holidays. Trained and standardized field workers used local cooking and serving utensils and a kitchen scale to assist in the estimation of portion size. The recipe for prepared foods was noted whenever possible and the quantity consumed of each food was recorded in grams. For the current analysis, all women with at least one $24-\mathrm{h}$ recall at recruitment and during the third trimester, baseline body mass index (BMI, $\mathrm{kg} / \mathrm{m}^{2}$ ) and socio-economic status were included.

The plausibility of reported consumption was assessed by comparing energy intake with recommendations for age and physiological status ${ }^{15,16,17}$ and the original questionnaires of interviews that resulted in extremely low or high intakes were reviewed. No data were eliminated as a result of this cleaning step. Individual variability between days was compared using analysis of variance at each time point (recruitment and third trimester). Variation coefficients were also calculared with and between subjects and variance ratio was calculated in recruitment and third trimester. Between-day variability was similar. Dietary intake over the two days of recall at each measurement interval was averaged and nutrient intake was determined using a compilation of four food composition tables that has been developed for use by INSP researchers for studies in Mexico (INSP, unpublished).

The same nurses were previously trained and standardized for all anthropometric measurements, demographic and socio-economic information for each participant was collected at recruitment by trained nurses. An index of socio-economic status was created using Principal Components Analysis based on information on housing construction materials and possession of domestic goods. ${ }^{18}$ BMI greater than 25.0 was used to classify adult women as overweight or obese ${ }^{19}$ (combined for this analysis) and the cut-off point suggested by Rolland-Cachera ${ }^{20}$ was used for women under the age of 18 years at recruitment.

To determine whether overweight or obesity were associated with lower reported dietary intakes, energy intake for overweight or obese women was compared with women with normal weight, the number of women with and without overweight or obesity who reported intakes below $1000 \mathrm{kcal}$ on average per day was then calculated. The Estimated Average Requirement (EAR) cut-point method proposed by Beaton ${ }^{21}$ was used for estimation of prevalence of adequate nutrient intake. Using this method, the prevalence of inadequate intakes is estimated as the proportion of the population with intakes below the median requirement. This method is not a recommendation for assessing the adequacy of energy intake because it is known that intakes and requirements are correlated. ${ }^{15}$

The distribution of dietary intake of energy and micronutrients was reviewed for normality by comparing mean and median values and kurtosis. Unadjusted group comparisons were made using t-test, $\mathrm{chi}^{2}$ for normally distributed variables and Kruskal-Wallis and Wilcoxon test for paired data for non-normally distributed variables. ${ }^{22}$ If nutrient intake by group differed in the univariate analysis, multiple linear regression was used to determine the impact of MM supplementation on dietary intake during the third trimester after adjustment for baseline characteristics that differed by supplementation group. The change in intake from baseline to third trimester for each nutrient was also calculated and tested in a similar manner. For all micronutrients, models were also adjusted for total energy intake using the standard multivariate method. ${ }^{23}$ Model diagnostics were assessed to ensure that the assumption of normality of residuals and independence of variables were not violated. Energy and nutrient content of the diet were assessed using a special program designed in Visual FoxPro, Version 6.0 (Microsoft Visual FoxPro, Microsoft Corporation, Redmond, Washington) and data analyses were conducted in STATA, Version 6.0 (Stata Co., Santa Monica, CA) and SPSS, Version 10 (Statistical Package for the Social Sciences, Chicago, Il).

\section{Results}

A total of 873 women were assigned to treatment; 436 to the MM supplement and 437 to the iron only supplement. The present analysis includes 463 (MM n=230; iron only $\mathrm{n}=233$ ) women who completed the study, had at least one 24-hr recall at recruitment (4-13 weeks) and in the third trimester (26-40 weeks) of pregnancy and had baseline anthropometric, demographic and socioeconomic information available (figure 1). The mean time between the two measurements was $5.5 \pm 0.6$ months, with a minimum of 2.1 months. There were no significant differences between the supplementation groups in the time between measurements. During the third year of the trial, the 24-hr recall was dropped from the third trimester due to resource limitations.

The reasons for dropout from the supplementation trial are published in detail elsewhere ${ }^{13}$ and include lack of family support and change of address out of the study area. There were no statistically significant differences between dropouts and those who completed the study in age, civil status, schooling or BMI. There were, however, statistically significant differences between those 

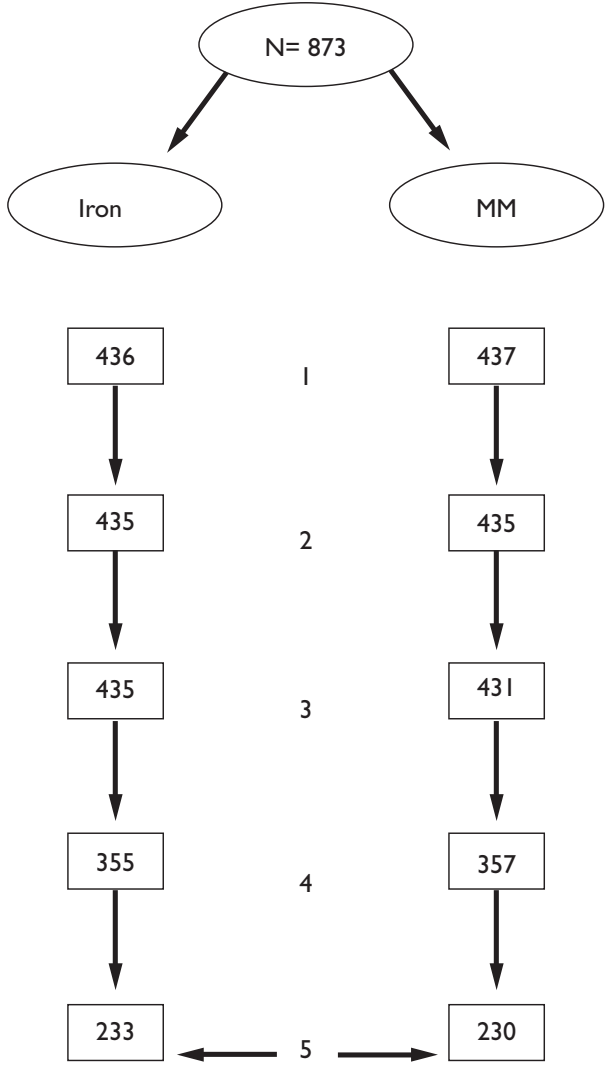

Figure I. SAMPLe of WOMEN INCLUding IN THE ANALYSis: I. Pregnant women recruited 2. Women With socioecoNOMIC DATA, 3. WOMEN WITH ANTHROPOMETRIC DATA, 4. WOMEN WITH AT LEAST ONE 24 HR RECALLS AT RECUITMENT, 5. WOMEN WITH AT LEAST ONE 24 HR RECALLS AT WEEK 32 OF PREGNANCY

with complete information for inclusion in the dietary intake analysis and those excluded due to drop out or missing data with respect to duration of pregnancy at recruitment, work outside the home, socioeconomic index and vitamin A intake (table I).

For the subsample included here, women in the MM group had significantly $(p<0.05)$ lower BMI $(23.6 \pm 3.8$ $\left.\mathrm{kg} / \mathrm{m}^{2}\right)$ and prevalence of overweight or obesity $(\mathrm{n}=68$, $29.6 \%$ ) at recruitment compared to women in the iron only group $\left(24.6 \pm 4.4 \mathrm{~kg} / \mathrm{m}^{2}\right.$, overweight or obese $\mathrm{n}=98$, $42.1 \%)$. Other measured variables were similar between the groups at recruitment (table II). This was also true for the entire sample recruited. ${ }^{13}$

Energy and micronutrient intakes were non-normally distributed, although the distribution was close to normal for energy and iron intake (Kurtosis $<4$ ). For consistency, median and interquartile range for all nutrient intakes are reported, but linear regression modeling is used to adjust for baseline BMI, with careful review that the assumptions of the model are not violated.

There was no difference in reported energy or micronutrient intake or in the prevalence of adequate intakes between supplementation groups at recruitment. Intakes of energy, iron, zinc, folic acid and vitamin A were significantly $(p<0.01)$ higher in the third trimester of pregnancy compared to recruitment for the entire sample (data not shown). There was also a tendency towards a higher prevalence of adequate zinc intakes in the micronutrient group ( $p=0.055$ ) (figure 2 ).

Median energy intake among women with overweight or obesity (1 $432 \mathrm{kcal}$, interquartile range 1101$1829 \mathrm{kcal}$ ) did not differ from that of women without overweight or obesity (1 $480 \mathrm{kcal}$, interquartile range $1131-1835 \mathrm{kcal}$ ). Findings were similar when women were divided by treatment group (data not shown). Among overweight or obese women, energy intakes of $<1000 \mathrm{kcal} / \mathrm{d}$ were estimated for $14(8 \%)$ women in the MM group and $18(10 \%)$ women in the iron only group $(p>0.05)$. There was no difference in the mean increase in energy between baseline and the third trimester between women with and without overweight or obesity.

There was a tendency $(p=0.05)$ towards higher energy intake among women in the MM compared to the iron only group during the third trimester of pregnancy in unadjusted group comparisons (table III). A similar tendency $(p=0.05)$ exists when energy is calculated as the increase in energy intake between baseline and third trimester (iron only $147 \pm 627 \mathrm{kcal}$; MM $266 \pm 728 \mathrm{kcal}$ ). Iron intake from recruitment to the third trimester increased, on average, $1.5 \pm 5.2 \mathrm{mg} / \mathrm{d}$ among women in the MM group and $0.5 \pm 4.5 \mathrm{mg} / \mathrm{d}$ among women in the iron only group $(p<0.05)$. There was no difference in dietary intake in the third trimester or in the change in average intake from recruitment to the third trimester between supplementation groups for any other nutrient.

After adjusting for differences between the groups at baseline (BMI), multiple micronutrient supplementation was associated with higher dietary energy intake (111 kcal/ d) compared to supplementation with iron only (table IV). A similar tendency was observed when change in energy intake from recruitment to the third trimester is used as the outcome variable, although this did not reach statistical significance $(p=0.05)$. MM supplementation is also associated with iron intake in the third trimester and change in iron intake from recruitment to the third trimester after adjustment for $\mathrm{BMI}$ at recruitment, but not after adjustment for change in energy intake. There were no differences in intakes 


\section{Table I \\ BASELINE CHARACTERISTICS OF WOMEN INCLUDED IN THE ANALYSIS AND THOSE LOST TO FOLLOW-UP OR WITH INCOMPLETE DATA}

\begin{tabular}{|c|c|c|c|}
\hline & $\begin{array}{l}\text { Included in the analysis } \\
\qquad(n=463)^{*}\end{array}$ & $\begin{array}{l}\text { Losses to follow-up and incomplete data } \\
\qquad(n=410)\end{array}$ & P-Value ${ }^{\ddagger}$ \\
\hline Age, years & $23.4 \pm 5.2$ & $23.5 \pm 5.5$ & NS \\
\hline $\mathrm{BMI}, \mathrm{kg} / \mathrm{m}^{2}$ & $24.1 \pm 4.1$ & $24.2 \pm 4.1$ & NS \\
\hline Duration of pregnancy, wks & $8.8 \pm 2.2$ & $5.7 \pm 4.7 \S$ & $<0.001$ \\
\hline Nulliparous, $n$ (\%) & $130(28)$ & $139(33.9)$ & NS \\
\hline Work outside the home, $\mathrm{n}(\%)$ & $143(30.8)$ & $370(90.2)$ & $<0.001$ \\
\hline Completed primary school, n (\%) & $353(76.2)$ & $318(77.5)$ & NS \\
\hline Index of economic status," n (\%) & & & $<0.001$ \\
\hline Low & $179(38.6)$ & $286(63.7)$ & \\
\hline Middle & $116(25)$ & $46($ (II.2) & \\
\hline High & $168(36.2)$ & $78(19)$ & \\
\hline Energy, kcal & I 46I $\quad(I \mid I 9,1835)$ & $1466(1106,1818)^{8}$ & NS \\
\hline Iron, mg & $9.3 \quad(7.3,12.1)$ & $8.9 \quad(7,11.8)$ & NS \\
\hline Zinc, mg & $5.7 \quad(4.3,7.5)$ & $5.3(4.3,7)$ & NS \\
\hline Folic acid, $\mu g$ & $220.7(143.3,306.9)$ & $205.7(150,311.8)$ & NS \\
\hline Vitamin $A, \mu g R E$ & $468.2(279.1,1038.9)$ & $606 \quad(331,8 \mid 179.5)$ & $<0.05$ \\
\hline Vitamin C, mg & $55.2 \quad(30.5,105.5)$ & $62.6(32.5,115.2)$ & NS \\
\hline \multicolumn{4}{|c|}{$\begin{array}{l}\text { * Mean } \pm \text { SD, unless otherwise specified. Data for nutrient intakes presented as median (interquartile range) } \\
\text { † Statistical testing using t-test for continuous variables, Kruskal-Wallis test for energy and nutrient intakes, and chi' for categorical variables } \\
\S n=407 \\
\text { \# Based on housing construction materials and domestic possessions, using Principal Components Analysis. }{ }^{22} \text { Low, middle, high based on tertiles of the current } \\
\text { population } \\
\& \text { n=238 for estimated dietary intake, including all nutrients reported here }\end{array}$} \\
\hline
\end{tabular}

Table II

\section{Characteristics of Study Participants AND dietary INTAKe AT RECRUITMENT}

\begin{tabular}{|c|c|c|}
\hline & Iron only* & Multiple micronutrients \\
\hline Age,yrs & $23.7 \pm 5.4$ & $23.0 \pm 5.1$ \\
\hline $\mathrm{BMI},{ }^{\ddagger} \mathrm{kg} / \mathrm{m}^{2}$ & $24.6 \pm 4.4$ & $23.6 \pm 3.8$ \\
\hline Duration of pregnancy, wks & $8.8 \pm 2.2$ & $8.9 \pm 2.2$ \\
\hline Nulliparous, n (\%) & $58(24.8)$ & $72(31.3)$ \\
\hline Work outside the home, n (\%) & $72(30.9)$ & $71(30.8)$ \\
\hline Completed primary school, n (\%) & $182(78.1)$ & I7I (74.3) \\
\hline \multicolumn{3}{|l|}{ Index of economic status, ${ }^{\S} \mathrm{n}(\%)$} \\
\hline Low & $87(37.3)$ & $92(40.0)$ \\
\hline Middle & $56(24.0)$ & $60(26.1)$ \\
\hline High & $90(38.6)$ & $78(33.9)$ \\
\hline Energy, kcal & I $430 \quad(|I 3|, \mid 842)$ & $|46| \quad(|I 06| 822)$, \\
\hline Iron, mg & $9.2 \quad(7.4,12.0)$ & $9.4 \quad(7.1,12.2)$ \\
\hline Zinc, mg & $5.7 \quad(4.5,7.3)$ & $5.6 \quad(4.1,7.5)$ \\
\hline Folic acid, $\mu g$ & $220.2(146.0,306.9)$ & $221.0(140.2,303.7)$ \\
\hline Vitamin $A, \mu g R E$ & $468.3(298.8,1028.9)$ & $463.1(256.1, I 169.5)$ \\
\hline Vitamin C, mg & $62.5 \quad(33.9,106.7)$ & $48.4 \quad(26.3,96.1)$ \\
\hline
\end{tabular}

Morelos state, Mexico, 1997-2000 


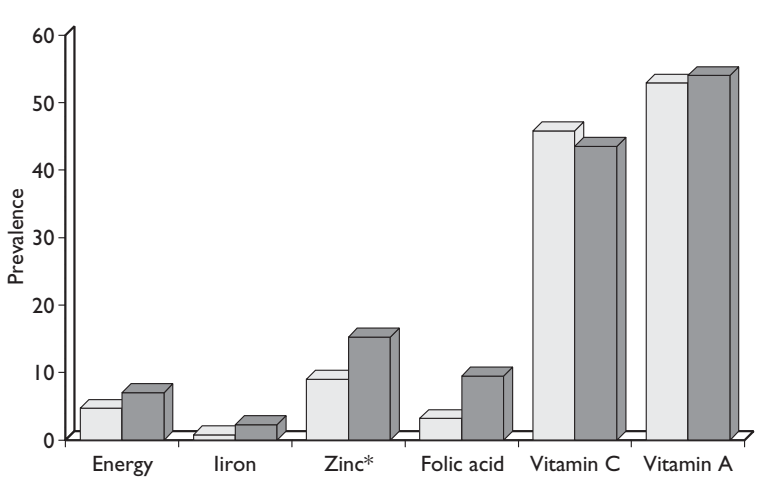

White bars= Iron only $(n=233)$; grey bars = multiple micronutrients $(n=230)$, $* p=0.055$

Figure 2. Prevalence of adeQuate reported usual dietaRY INTAKE OF ENERGY AND SELECT MICRONUTRIENTS DURING THE THIRD TRIMESTER OF PREGNANCY ESTIMATED USING THE EAR CUT-POINT METHOD. ${ }^{15,16,17}$

between recruitment and the third trimester for any of the other micronutrients estimated after adjustment for change in energy intake.

\section{Discussion}

In this randomized, controlled trial a positive effect was found of MM supplementation on dietary energy and iron intake during pregnancy. Because the impact on iron was not significant after adjusting for the increase in energy intake, it is likely that micronutrient density in the diet did not change. Although the absolute daily increase in energy intake is small $(111 \mathrm{kcal} / \mathrm{d}$
Table III

DietARY ENERGY AND MICRONUTRIENT INTAKE BY SUPPLEMENTATION GROUP IN THE THIRD TRIMESTER OF PREGNANCY

\begin{tabular}{|c|c|c|c|}
\hline \multirow[b]{2}{*}{ Energy, ${ }^{2} \mathrm{kcal}$} & \multirow[b]{2}{*}{1575} & \multirow{2}{*}{$\begin{array}{l}\text { Iron only* } \\
(1266,1937)\end{array}$} & Multiple micronutrients \\
\hline & & & $(I 348,2037) A$ \\
\hline Iron, ${ }^{3} \mathrm{mg}$ & 10.5 & $(7.9,11.9)$ & $10.7 \quad(8.6,13.3)$ \\
\hline Zinc, mg & 5.9 & $(5.0,7.4)$ & $(5.2,8.0)$ \\
\hline Folic acid, $\mu \mathrm{g}$ & \multicolumn{2}{|c|}{$238.1(159.6,317.0)$} & $231.3(166.6,334.1)$ \\
\hline Vitamin A, $\mu g R E$ & \multicolumn{2}{|c|}{$583.0(307.7,1090.3)$} & $618.4(324.8,1382.1)$ \\
\hline Vitamin C, mg & 59.7 & $(32.8,99.8)$ & $61.2 \quad(32.8,107.3)$ \\
\hline
\end{tabular}

* Median (interquartile range). Statistical testing for difference in median between supplement groups using Kruskal-Wallis tes ${ }^{22}$

$\ddagger 0.05<p<0.10$

$\S p<0.05$

Morelos state, Mexico, 1997-2000

after adjusting for baseline differences in BMI between the supplementation groups), this increase may have important implications for maternal nutritional status and, therefore, pregnancy outcome if energy intake is a limiting factor. In Mexico, where the prevalence of overweight and obesity among women has reached near epidemic proportions, ${ }^{5}$ it is unlikely that this additional energy will have a positive contribution to the outcome of pregnancy. Although the magnitude of the impact reported here is small, the potential implications of additional energy intake during pregnancy on weight gain and retention needs to be further investigated.

The additional energy intake observed in this study could have been used to improve fetal growth

Table IV

DifFERENCE IN ENERGY AND IRON INTAKE BY SUPPLEMENTATION GROUP AFTER ADJUSTMENT FOR BASELINE BMI

\begin{tabular}{|c|c|c|}
\hline & Energy (kcal) & Iron (mg) \\
\hline Intake in third trimester & $111.3 \pm 52.3^{*}$ & $1.00 \pm 0.33^{\ddagger}$ \\
\hline Intake in third trimester $\S$ & - & $0.45 \pm 0.20 *$ \\
\hline Difference in intake between recruitment and third trimester & $124.9 \pm 63.5^{\#}$ & $\mathrm{I} . \mathrm{II} \pm 0.46 *$ \\
\hline Difference in intake between recruitment and third trimester $\underline{\underline{\ell}}$ & - & $0.41 \pm 0.29$ \\
\hline $\begin{array}{l}* p<0.05 \\
\ddagger p<0.01 \\
\S \text { Adjusting for BMI at recruitment and total energy intake }{ }^{23} \\
\# p=0.05 \\
\text { \& } \text { Adjusting for BMI at recruitment and change in energy intake }\end{array}$ & & \\
\hline Morelos state, Mexico, 1997-2000 & & \\
\hline
\end{tabular}


or increase maternal energy reserves, or may be reflected in greater energy expenditure through physical activity. In earlier analyses, no effect was found of MM supplementation on birth weight or length. ${ }^{13} \mathrm{MM}$ supplementation was associated with greater weight retention at (one month) postpartum but only among overweight or obese women. ${ }^{24}$ In this analysis, no evidence was found to indicate that the higher dietary energy intake among women who consumed the MM supplement was restricted to overweight or obese women (results not shown). Full breastfeeding (breastmilk plus small quantities of water and/or tea) at 1 mo postpartum is almost universal in this population. Additional energy reserves among women in the MM may have been used to meet higher maternal demands during this early period. Is is not possible to verify this hypothesis because this study does not have information with respect to maternal dietary intake, breast milk production or maternal weight measurements between delivery and 1 mo or after 1 mo postpartum.

Few studies have evaluated physical activity in pregnant women. Some evidence exists that pregnant women reduce their routine physical activity, becoming more sedentary or reducing the intensity of various activities..$^{25}$ The women who consumed the MM supplement may have increased or decreased to a lesser extent their activities during pregnancy, and thus used the additional dietary energy. Unfortunately, physical activity information was not collected from the participants of this study and it is not feasible to further investigate this possibility. Future research on the influence of MM supplements on dietary intake should include physical activity measurements.

Despite the random allocation of treatment, there was a difference in mean BMI and in the prevalence of overweight or obesity between supplementation groups at recruitment. Under-reporting of food intake has been observed among non-pregnant women with high BMI. ${ }^{26,27,28}$ Bergmann and coworkers ${ }^{29}$ found that European women with high BMI reported significantly lower energy intake at the beginning of pregnancy compared to women with normal or low BMI. In the current analysis, no difference was found in the number of individuals with low energy intake $(<1000 \mathrm{kcal} / \mathrm{d})$ between women with and without overweight or obesity nor was a difference found in median reported intake. It is therefore considered probable that underreporting of dietary intake is distributed randomly between supplementation groups, and it is unlikely that it has influenced the results reported here. Underreporting by overweight women may be related to the local perception of "overweight" as an undesirable state. It is possible that under-reporting of dietary intake is less common in this population because of a less negative perception of excess weight. To the knowledge of the authors of this study, the association between the social perception of weight status and under-reporting of dietary intake has not been documented in Mexico. Further understanding of this relationship would be very useful for the interpretation of dietary intake data from diverse populations.

Conventional wisdom suggests that due to less variety in food intake in developing countries, fewer days may be needed to capture usual intake. ${ }^{30}$ The number of days required to estimate intake depends on the intended use of the data; for example, estimation of causal intake in a population may not require the same degree of precision as does estimation of individual usual intake. ${ }^{31}$ In this study, there were two days of dietary recall for most women at recruitment and for all women during the third trimester. Although this was less than the ideal three to seven days to reflect usual intake, ${ }^{30}$ the repeat measures should help reduce error related to individual day-to-day variability in dietary intakes. Total dietary intake is likely still underestimated, as is common with the $24-\mathrm{hr}$ recall method. ${ }^{31} \mathrm{At}$ the same time, the intra-to-inter individual ratio in this study was $<1.0$ for energy wich is consistent with other studies that have evaluated the variability in nutrient intakes among pregnant women using the 24-h recall method. ${ }^{32}$ Furthermore, previous studies have found that variance ratios for micronutrients were generally langer than those for energy and macronutrients. This suggests that it would be more difficult to detect a statistically significant association between micronutrients intake, given the langer error associated with the estimation of micronutrient intakes. ${ }^{33,34}$ Hence, small increases of energy that are found are not due to measurement errors. This is confirmed by the contrast between the relatively high mean BMI of this population and the low average reported adequacy of energy intake (approximately $55 \%$ ).

The major strength of this analysis lies in the fact that it is a randomized double-blind trial, and although the absolute intakes may be underestimated, there is no reason to believe that there is a systematic difference in the extent of underestimation between supplementation groups. Thus, the finding of a greater increase in dietary energy intake among women consuming the multiple micronutrient supplement is unlikely to be affected by this methodological limitation.

Dietary intake is the principle source for supplying mother and fetus with the nutrients and energy necessary for optimal pregnancy outcome for both mother and newborn. In the context of micronutrient supplementation trials, it is important to determine the 
potential effect of supplementation on dietary intake as a potential mechanism for the impact of the intervention. In this randomized trial, greater dietary energy intake was found to be associated with MM compared to iron only supplementation, the results of which were not reflected in greater fetal size at birth ${ }^{13}$ but with evidence of greater maternal weight retention in the early postpartum period among overweight or obese women. ${ }^{22}$ The possibility that MM supplementation resulted in greater appetite, changes in the energy density of foods consumed and/or in energy expenditure should be evaluated in other populations, particularly those where energy intake may be a limiting factor for fetal growth or maternal and fetal well-being. Further studies with longer postpartum follow-up periods and extensive dietary and physical activity data collection would be useful to determine whether increased energy intake associated with MM supplementation may be of concern in populations with a high prevalence of overweight and obesity.

\section{Acknowledgements}

Support for this study was provided by the Thrasher Research Fund, UNICEF, CONACyT Mexico, the Department of International Health, Rollins School of Public Health, Emory University and the National Institute of Public Health from Mexico. These contributions are gratefully acknowledged.

\section{References}

I. Picciano MF. Pregnancy and lactation. In: Ziegler-Ekhard E, Filer LJ, ed. Present knowledge in nutrition. 7th Edition, Washington, DC: ILSI Press, 1996:384-395.

2. Lenders CM, McElrath TF. Nutrition in adolescent pregnancy. Curr Opin Pediatr 2000;12:291-296.

3. Beard JL. Effectiveness and strategies of iron supplementation during pregnancy.Am J Clin Nutr 2000;71:1288S-1294S.

4. Lapido OA. Nutrition in pregnancy: mineral and vitamin supplements. Am J Clin Nutr 2000;72 Suppl I:280S-290S.

5. Rivera DJ, Shamah LT,Villalpando HS, González de Cossío T, Hernández PB, Sepúlveda.J Nutritional status of children and women in México. Cuernavaca, México: National Institute of Public Health, $200 \mathrm{I}$.

6. Barquera S, Rivera JA, Espinosa-Montero J, Safdie M, Campirano F, Monterrubio EA. Energy and nutrient consumption in Mexican women 12-49 years of age:Analysis of the National Nutrition Survey, 1999. Salud Publica Mex 2003;45 suppl 4:S530-S539

7.Anderson AS, Lean ME. Dietary intake in pregnancy.A comparison between 49 Cambridge shire women and current recommended intakes. Hum Nutr Appl Nutr 1986;40:I-8.

8.Vitolins MZ, Quandt SA, Case LD, Bell RA, Arcury TA, McDonald J. Vitamin and mineral supplement use by older rural adults.J Gerontol Biol Sci Med Sci 2000;55:M613-M6I7.
9. Stoltzfus RJ, Chway HM, Montresor A, Tielsch JM, Jape JK,Albonico M, et al. Low dose daily iron supplementation improves iron status and appetite but not anemia, whereas quarterly anthelminthic treatment improves growth, appetite and anemia in Zanzibari preschool children.J Nutr 2004; 134:348-356.

10. McCarthy D,Weihofen D. The effect of nutritional supplements on food intake in patients undergoing radiotherapy. Oncol Nurs Forum 1999; 26:897-900.

II.Wilson CW.Appetite for vitamin C: its relationship to cellular energy potential. Int JVitam Nutr Res Suppl 1982;23:173-185.

12. Dossa AMR, Ategbo ED, Van Raaij MA, Graaf C, Hautvast GAJ. Multivitamin-multimineral and iron supplementation did not improve appetite of young stunted and anemic Beninese children.J Nutr 200I;|3।: 2874-2879.

I3. Ramakrishnan U, González-Cossio T, Neufeld LM, Rivera J, Martorell R. Multiple micronutrient supplementation during pregnancy does not lead to greater infant birth size than does iron-only supplementation: a randomized controlled trial in a semirural community in Mexico.Am J Clin Nutr 2003; 77: 720-725.

14. National Research Council. Recommended dietary allowance. 9th ed. Washington, DC: National Academy Press, 1980.

15. Institute of Medicine. Dietary reference intakes: applications in dietary assessment: a report of the of the Subcommittees on Interpretation and Use of Dietary Reference Levels of Nutrients, and the Standing Committee on the Scientific Evaluation of Dietary Reference Intakes. Washington, DC: National Academy Press, 2001:81-93.

16. Institute of Medicine. Dietary reference intakes for vitamin A, vitamin $\mathrm{K}$, arsenic, boron, chromium, copper, iodine, iron, manganese, molybdenum, nickel, silicon, vanadium, and zinc. Washington, DC: National Academy Press, 2001:770-773.

17. Institute of Medicine Dietary Reference Intakes for Energy, Carbohydrate, Fiber, Fat, Fatty Acids, Cholesterol, Protein, and Amino Acids (Macronutrients),Washington, DC: National Academy Press, 2002: I- 10.

18. Kleinbaum DG, Kupper LL, Muller KE.Applied regression analysis and other multivariate methods. 2nd edition. Boston: PWS-Kent Publishing Company, 1988.

19. World Health Organization Obesity. Preventing and managing the global epidemic. Report of a WHO Consultation on Obesity. Geneva: WHO, 1997.

20. Rolland-Cachera MF, Cole TJ, Sempe M, Tichet J, Rossignol C, Charraud A. Body Mass Index variations; centiles from birth to 87 years. Eur J Clin Nutr 199|; 45:|3-2|

21. Beaton GH, Milner J, McGuire V, Feather TE, Little JA. Source of variance in 24-hour dietary recall data: Implications for nutrition study design and interpretation. Carbohydrate source, vitamins, and minerals. Am J Clin Nutr 1983;37:986-995.

22. Conover WJ. Practical Nonparametric Statistics. New York:Wiley \& Sons, 1980.

23. Willett W. Howe R, Kushi LH.Adjustment for total energy intake in epidemiologic studies. Am J Clin Nutr 1997;65: I220S- 228 S.

24. Ramakrishnan U, González-Cossio T, Neufeld LM, Rivera J, Martorell R. Effect of Prenatal Multiple Micronutrient Supplements on maternal weight and skinfold changes: A Randomized double-blind clinical trial in Mexico. Food Nutr Bull 2005;26:273-280

25. King JC. Physiology of pregnancy and nutrient metabolism. Am J Clin Nutr 2000;7I:Suppl 5:SI2I8-SI225.

26. Kant AK. Association of self-perceived body weight status with dietary reporting by US teens. Obes Res 2002;10:1259-1269.

27. Gnardellis C, Boulou C, Trichopoulou A. Magnitude, determinants and impact of under-reporting of energy intake in a cohort study in Greece. Public Health Nutr 1998;1:131-137.

28. Poppitt SD, Swann D, Black AE, Prentice AM. Assessment of selective under-reporting of food intake by both obese and non-obese women in a metabolic facility. Int J Obes Relat Metab Disord 1998;22:303-3I I. 
29. Bergmann MM, Flagg EW, Miracle-McMahill HL, Boeing H. Energy intake and net weight in pregnant women according to body mass index (BMI) status. Int J Obes Relat Metab Disord 1997;21:1010-1015.

30.Willett W. Nature of variation in diet. In: Nutrition Epidemiology. New York: Oxford University Press, 1990:34-5I.

3I. Beaton GH,Approaches to analysis of dietary data: relationship between planned analyses and choice of methodology. Am J Clin Nutr 1994:59:S253-S26I.

32. Nelson M Assessment of food consumption and nutrient intake. In: Nelson M, Bingham SA, eds. Design Concepts in Nutrition Epidemiology. New York: Oxford University Press, 1991:138-160.
33. Persson V,Winkvist A, Harina TNS, Creiner T, Hakimi M, Stenlund H. Variability in nutrient intakes among pregnancy women in Indonesia: implications for the design of epidemiological studies using the 24-h recall method. J Nutr 200I; I3I:I35-330.

34. Nyambose J, Koski, KG, Tucker KL, High intra/interindividual variance ratios for energy and nutrients intakes of pregnant women in rural Malawi show that many days are required to estimate usual intake.J Nutr 2002;132:1313-1318. 